\title{
Formigas veiculadoras de bactérias patogênicas em uma drogaria no Município de Alagoinhas-BA
}

\author{
Pathogenic bacteria carrier ants in a farmacy in the city of Alagoinhas-BA \\ J. B. Souza ${ }^{1 *} ;$ E. S. Conceiçãa $0^{2 ;}$ E. J. Marques ${ }^{2}$ \\ ${ }^{1}$ Programa de Pos-Graduação em Ciências Fisiológicas, Universidade Federal de Sergipe, 49100-000, São Cristóvão- \\ Sergipe, Brasil \\ ${ }_{2}^{2}$ Departamento de Ciências Exatas e da Terra, Universidade do Estado da Bahia, 48000-000, Alagoinhas-Bahia, \\ Brasil \\ *jes_sica_bio@hotmail.com.br
}

(Recebido em 25 de agosto de 2019; aceito em 02 de dezembro de 2019)

\begin{abstract}
Formigas são insetos em que há capacidade de aderir microrganismos e então de disseminá-los no ambiente durante a sua locomoção, que é rápida e eficiente. Sendo então consideradas carreadoras de bactérias e também uma via de transmissão de infecções em hospitais e postos de saúde, podendo constituir uma ameaça à saúde pública. $\mathrm{O}$ objetivo deste estudo foi verificar se as formigas presentes em uma drogaria no município de Alagoinhas-Bahia eram veiculadoras de bactérias patogênicas. As formigas foram coletadas manualmente, utilizando-se pinças e pedaços de algodão estéreis, bem como iscas atrativas de mel, nos meses de julho e outubro de 2015. O material microbiológico proveniente das formigas foi cultivado em tubos de ensaios, contendo caldo (Brain Heart Infusion) BHI e incubado em estufa a $35^{\circ} \mathrm{C}$ por 24 horas. A partir dos tubos, que apresentaram crescimento bacteriano, foram realizadas diluições seriadas, seguidas da semeadura por esgotamento em estrias, em placas contendo meio de cultura Ágar nutriente. As colônias de bactérias isoladas foram submetidas a ensaios de coloração de Gram e testes bioquímicos de identificação rápida. As formigas coletadas para avaliação foram armazenadas em álcool a $70 \%$ até a identificação. Tapinoma melanocephalum e Pheidole sp1 foram as únicas espécies encontradas, sendo T. melanocephalum a mais frequente. Cocos Gram-positivos pertencentes à família Streptococcacea e Micrococcacea foram detectados. Através do presente estudo foi demonstrado que as formigas supra-citadas podem carrear bactérias patogênicas e isso representa risco de contaminação às pessoas e aos medicamentos.

Palavras-chave: pragas-urbanas,contaminação, saúde-pública.
\end{abstract}

Ants are insects that are able to adhere microorganisms and then to spread them in the environment during their fast and efficient movement. Therefore, they are considered carrier of bacterias and also a infection transmission pathway in hospitals and health posts, and may constitute a threat to public health. The aim of this study was to verify if the ants present in a farmacy in the municipality of Alagoinhas-Bahia were carriers of pathogenic bacteria. The ants were collected manually using sterile cotton tweezers and pieces, as well as attractive honey baits, in July and October 2015. Microbiologial material from ants was grown in test tubes containing (Brain Heart Infusion) BHI broth and incubated in a greenhouseat $35^{\circ} \mathrm{C}$ for 24 hours. From the tubes, which showed bacterial growth, serial dilutions were performed, followed by streaking, in plates containing nutrient agar culture medium. Colonies of isolated bacteria were subjected to Gram staining assays and rapid identification biochemical tests. The ants collected for evaluation were stored in $70 \%$ alcohol until identification. Tapinoma melanocephalum and Pheidole sp1 were the only species found, being $T$. melanocephalum the most frequent. Gram-positive cocci belonging to the family Streptococcacea and Micrococcacea were detected. Through the current study it was demonstrated that the above mentioned ants can carry pathogenic bacteria and this poses risk of contamination to people and medicines.

Keywords: uban pests, contamination, public healf.

\section{INTRODUÇÃO}

As formigas são insetos que obtiveram grande sucesso na ocupação do ambiente terrestre e estão geograficamente onipresentes [1]. São em geral oportunistas e na busca por alimento, circulam em muitos lugares comumente frequentados, incluindo ambientes onde são indesejáveis, tais como, escolas, hospitais e unidades de alimentação, provocando incômodos e estragos em suas estruturas [2-5]. 
Se por um lado são benéficas, quando contribuem para ciclagem de nutrientes, aeração do solo, polinização, dispersão de sementes e também por participar da cadeia alimentar [1, 6]. Por outro, das espécies adaptadas ao ambiente urbano, cerca de 20 a 30 podem ser consideradas pragas urbanas, por causar conflito com os interesses do homem [3, 4, 7]. Embora a ocorrência desses artrópodes seja restrita a poucas espécies, os prejuízos que causam podem ser grandes, principalmente quando nidificam em unidades de saúde, pois, podem se apresentar como veiculadoras de microrganismos patogênicos $[8,9]$.

As formigas são importantes carreadoras bactérianas e, portanto, atuam como um veículo na transmissão de infecções às pessoas. Podem passar por ambientes contaminados: lixo, cano de pias e esgoto. Ou mesmo em material humano: fezes, secreções e sangue. Podendo, dessa maneira, ter aderido ao seu corpo bactérias e disseminá-las para o ambiente, contaminando alimentos, instrumentos cirúrgicos; além de pessoas $[4,5,7,10]$.

De maneira geral, as infecções humanas podem ocorrer através da microbiota endógena; por contaminação cruzada ou por meio do ambiente, a microbiota exógena $[2,11,12]$. Em drogarias, há possibilidade de as pessoas serem infectadas por meio de contaminação cruzada e por microbiota exógena. A primeira poderá ocorrer durante a aplicação de medicamentos injetáveis, perfuração de orelha e aferição de glicemia capilar; a segunda, umas das formas seria pela ingestão de medicamentos contaminados. Nas caixas de medicamentos, as formigas encontram um ambiente propício para a formação de ninho [13]. Algumas espécies são, inclusive, atraídas por embalagens de medicamentos adocicados $[12,14,15]$. Se houver algum contaminado, aumenta-se o risco de infecção por ingestão ou injeção medicamentosa.

Os clientes de uma drogaria, muitas vezes, são pacientes pré-hospitalizados e, ao receberem alta, saem diretamente para esses estabelecimentos em busca de medicamentos. Podendo, inclusive, se tratar de alguns da classe de antibióticos, usados para o tratamento de algum tipo de infecção. Os pacientes com doenças clínicas diversas e/ou de idade avanção são considerados o grupo de maior vulnerabilidade às infecções. Nesse contexto, deve-se ter atenção à questão da contaminação dos medicamentos em farmácias. Diversos estudos foram realizados sobre formigas urbanas em hospitais $[10,14,16,17-20]$. Sendo assim, o objetivo deste estudo foi verificar se formigas encontradas em uma drogaria no município de Alagoinhas-Bahia veiculam bactérias patogênicas.

\section{MATERIAL E MÉTODOS}

A coleta das formigas para as análises ocorreu nos meses de julho e outubro de 2015, em quatro recintos de uma drogaria, no município de Alagoinhas-Bahia: (1) depósito de medicamentos; (2) sala de aplicação de medicamentos injetáveis; (3) balcão de vendas e (4) perfumaria (estoque de mercadorias diversificadas). Dois procedimentos foram realizados para coletá-las: um destinado à indicação das espécies mais frequentes e outro para verificar a existência de bactérias veiculadas por elas. Para as coletas, utilizaram-se criotubos contendo isca de mel, com a finalidade de atraílas. Para a análise microbiológica, as coletas foram manuais com o uso de materiais estéreis [13, $21,22]$.

Dez iscas foram distribuídas em cada setor, observando-se os pontos de maior movimentação de formigas: frestas na parede, próximos ao bebedouro e a pia. Após 3 horas de exposição das iscas, os criotubos foram recolhidos.

A coleta manual foi baseada em Silva (2009) [22]. Após sondar os recintos da drograria, ao visualizar uma formiga, um pedaço de algodão de aproximadamente $5 \mathrm{~cm}$ de diâmetro era levemente tocado em seu dorso. Essa formiga, já contida, era retirada com o auxílio de uma pinça e acondicionada em criotubos. Nessas condições, foram coletadas três formigas por setor, totalizando 12 por período de coleta, uma por criotubo.

Após a coleta, as formigas foram conduzidas à Universidade do Estado da Bahia, Campus II, para serem avaliadas. Inicialmente $100 \mu \mathrm{l}$ de solução salina foram micropipetados em cada criotubo que continha apenas um espécime e transferidos para tubos de ensaio com $10 \mathrm{~mL}$ de caldo BHI (Brain Heart Infusion) [9]. Os tubos de BHI foram incubados em estufa a $35^{\circ} \mathrm{C}$ por $24 \mathrm{~h}$ e, em seguida, aqueles que acusaram presença de bactérias (turvaram) foram submetidos a diluições seriadas por tês vezes $10^{-1} ; 10^{-2} \mathrm{e} 10^{-3} \mathrm{~mL}$. Posteriormente às diluições pretendidas, o material foi 
semeado em placas contendo meio Ágar Nutriente, atráves do esgotamento por estrias, para a obtenção de colônias isoladas e então, incubadas em estufa a $37^{\circ} \mathrm{C}$ por $24 \mathrm{~h}$.

A identificação das bactérias ocorreu por meio da técnica de coloração Gram e também por testes bioquímicos de identificação rápida, de acordo com as recomendações do fabricante [23]. A prova da catalase foi realizada com as bactérias gram positivas, para diferenciação entre estreptococos e estafilococos [15]. O teste de coagulase (aglutinação em latex) consistiu na utilização do kit "Staphylin" para diferenciação entre Staphylococcus aureus (formação de coágulo) $e$ Staphylococcus coagulase negatico (SCN).

Após análises microbiológicas, as formigas foram conservadas em álcool a 70\%, até que fossem montadas e identificadas. A identificação das mesmas ocorreu no Laboratório de Zoologia, de acordo com Bolton (2003) [24], Bolton et al. (2007) [25] e Conceição et al. (2019) [26].

\section{RESULTADOS E DISCUSSÃO}

Apenas duas espécies de formigas foram encontradas nos ambientes: Pheidole sp1 (Myrmicinae) e Tapinoma melanocephalum (Dolichoderinae). Essas espécies variaram em frequências, mas $T$. melanocephalum foi a que ocorreu com maior frequência durante todo o período do estudo. Não houve uma diferença, em relação ao período de coleta, que se destacasse (Tabela 1).

Tabela 1. Frequência de formigas por setor e período em uma drograria do Município de Alagoinhas-BA.

\begin{tabular}{|c|c|c|c|c|c|c|c|c|}
\hline \multirow{3}{*}{ Espécie } & \multicolumn{8}{|c|}{ Período/Frequência (F\%) } \\
\hline & Jul & Out & Jul & Out & Jul & Out & Jul & Out \\
\hline & \multicolumn{2}{|c|}{$\mathrm{DM}$} & \multicolumn{2}{|c|}{ SA } & \multicolumn{2}{|c|}{$\mathrm{BV}$} & \multicolumn{2}{|c|}{$\mathrm{P}$} \\
\hline Pheidole sp1 & 0 & 0 & 10 & 50 & 0 & 0 & 20 & 10 \\
\hline Tapinoma melanocephalum & 20 & 20 & 10 & 30 & 30 & 10 & 20 & 30 \\
\hline
\end{tabular}

Espécies do gênero Pheidole bem como de Tapinoma são as mais comumente encontradas em ambientes urbanos [5, 8, 14, 27]. Os ninhos de formigas urbanas, a exemplo, de Pheidole megacephala e T. melanocephalum, normalmente têm múltiplas rainhas, por isso tendem a dominar os habitats [28]. Além disso, as castas de rainhas possuem alta longevidade podendo viver de 2 a 4 anos. O longo período de vida dessas formigas e a tendência de multiplicação de seus ninhos fazem delas dominantes em um ambiente, por longos períodos.

De modo geral, as iscas foram dominadas por uma única espécie de formiga, $T$. melanocephalum, indicando que esta não permitiu que outras espécies se aproximassem. As formigas normalmente possuem agressividade interespecífica [29] e, quando existe dominância de somente uma espécie, a disseminação de bactérias é facilitada, devido ao livre deslocamento das operárias entre as várias repartições, contribuindo potencialmente para a contaminação do ambiente [30]. Além disso, esta espécie é adaptada ao ambiente urbano e comprovadamente veiculadora de microrganismos patogênicos em diversos ambientes [14, 31].

São muitos os estudos de inventários de formigas em ambientes urbanos, sobretudo em ambientes hospitalares, que apresentam T. melanocephalum ou Pheidole sp. como as principais espécies e/ou gênero amostrados [28, 32]. Vale salietar que a presença de formigas em um ambiente não significa necessariamente a falta limpeza, algumas espécies urbanas preferem locais higienizados e são, inclusive, atraídas por materiais estéreis [14].

Do total de 24 espécimes de formigas coletadas para a análise microbiológica, nove $(35,5 \%)$ apresentaram potencial veiculador de bactérias. Destes, 27,6\% corresponderam a $T$. melanocephalum e apenas 7,9\% a Pheidole sp. Os espécimes de T. melanocephalum coletados na maioria dos setores apresentaram microrganismos (Tabela 2). Esse potencial veiculador já foi comprovado por Campos-Farinha e Bueno (2004) [29] e outros autores [14, 31]. 
Tabela 2 - Número de ocorrência de espécies de formigas impregnadas de bactérias em uma farmácia do município de Alagoinhas-BA em julho e outubro de 2015.

\begin{tabular}{|c|c|c|c|c|c|}
\hline \multirow[b]{2}{*}{$\begin{array}{l}\text { Mês de } \\
\text { coleta }\end{array}$} & \multirow[b]{2}{*}{ Formigas } & \multicolumn{4}{|c|}{$\mathrm{N}^{\circ}$ de formigas impregnadas de bactérias/setor } \\
\hline & & DM & $\mathrm{SA}$ & $\mathrm{BV}$ & $\mathrm{P}$ \\
\hline Julho & T. melanocephalum & $\begin{array}{c}2 \text { sp. } \\
\text { Microccocacea } / S \\
\text { aureus }\end{array}$ & $0 \mathrm{sp}$. & $\begin{array}{c}1 \mathrm{sp} . \\
\text { Streptococcacea }\end{array}$ & $\begin{array}{c}2 \mathrm{sp} . \\
\text { Streptococcacea }\end{array}$ \\
\hline \multirow[b]{2}{*}{ Outubro } & Pheidole sp1 & 0 & 0 & 0 & $\begin{array}{c}1 \\
\text { Streptococcacea }\end{array}$ \\
\hline & T. melanocephalum & $\begin{array}{c}1 \mathrm{sp} . \\
\text { Streptococcacea }\end{array}$ & $\begin{array}{c}1 \mathrm{sp} . \\
\text { Streptococcacea }\end{array}$ & $\begin{array}{c}1 \mathrm{sp} . \\
\text { Streptococcacea }\end{array}$ & $0 \mathrm{sp}$. \\
\hline
\end{tabular}

$\overline{\text { DM-Déposito de medicamentos; SA- Sala de aplicação; BV- Balcão de vendas; P- Perfumaria; sp- espécies. }}$

Os ensaios microbiológicos revelaram a presença de bactérias da família Streptococcacea e Microccocacea veículadas às formigas. Todavia houve predominância da Streptococcacea em praticamente todos os setores da drogaria. A ocorrência de Microccocacea foi observada somente no déposito de medicamentos e no mês de julho. Desta, Staphylococcus aureus foi a única espécie observada (Tabela 2).

A capacidade que as formigas têm para aderência de microrganismos aos seus corpos se deve à presença de pêlos nestas, à escultura da cutícula e a distribuição das glândulas exócrinas, que podem servir como uma forma de adesão e sobrevivência de microrganismos em seu tegumento. Entretanto, ainda não existem estudos relacionando a complexidade da morfologia externa das formigas com o índice de contaminação apresentado por elas [14].

Bactérias da família Microccocacea compreendem os gêneros: Planococcus, Micrococcus, Stomatococcus e Staphylococcus [33]. Este último está entre os microrganismos que realizam simbiose com formigas, sendo um dos principais causadores de infecções hospitalares [4, 9, 14, 34]. Podendo provocar infecções simples, tais como espinhas, foliculite simples, furúnculos, carbúnculos e impetigo; até as mais graves enfermidades: pneumonia, meningite, endocardite, síndrome do choque tóxico, septicemia, entre outras [33,15].

As infecções por $S$. aureus ocorrem majoritariamente pelo comprometimento do sistema imune do hospedeiro, uso de dispositivos médicos e de procedimentos invasivos [22, 34]. Paralelo a isso, o gênero Streptococcus, formado por um grupo diverso de Cocos Gram-positivos, cuja identificação das espécies é muito complexa. Também é reconhecido por constituir-se de importantes espécies patogênicas: $S$. pyogenes, associada à formação de pus nas feridas; $S$. pneumoniae, causa a pneumonia; S. anginosus, abscessos cerebrais; S. bovis, câncer gastrointestinal e meningite; S. suis, síndrome do choque tóxico estreptocócico [35]. Dessa forma, a presença dessas bactérias na drogaria em questão, sobretudo no depósito de medicamentos, é um risco à saude para as pessoas, e cuidados preventivos devem ser tomados para evitar a contaminação dos medicamentos.

\section{CONCLUSÃO}

O estudo revelou a capacidade das formigas T. melanocephalum e Pheidole sp1 serem veiculadoras de bactérias na drogaria avaliada, sendo T. melanocephalum a espécie mais frequente e a que apresentou mais bactérias. A ocorrência dessas formigas na drogaria pode elevar o risco de contaminação por bactérias da família Microccocacea e Streptococcacea, o que demonstra a necessidade de mais estudos sobre o potencial das formigas como agentes disseminadores de patógenos causadores de doenças e maior atenção a esse aspecto na rotina de estabelecimentos.

\section{AGRADECIMENTOS}

A Universidade do Estado da Bahia, campus II, pela disponibilização dos laboratórios e recursos materiais. 


\section{REFERÊNCIAS BIBLIOGRÁFICAS}

1. Fleck MD, Cantarelli EB, Granzotto F. Registro de novas espécies de formigas (Hymenoptera: Formicidae) no estado do Rio Grande do Sul. Ci Fl. 2015 Jun;25(2):491-499, doi: $10.5902 / 1980509818468$

2. Castro MM et al. Formigas em ambientes urbanos: importância e risco à saúde pública. Ces Rev. 2014 Dez;28(1):103-117.

3. Lutinski JA et al. Ants (Hymenoptera: Formicidae) in hospitals of southern Brazil. Rev Colomb Entomol. 2015 Dez;41(2):235-240.

4. Carrecelli CB; Barcelos D. Identification of Staphylococcus epidermidis on ants (Hymenoptera: Formicidae) collected in a food court in the city of Guarulhos, São Paulo. Arq Inst Biol. 2017 Out;84(1):1-5, doi: 10.1590/1808-1657000652015

5. Guarda $\mathrm{C}$ et al. Assembleia de formigas (Hymenoptera: Formicidae) em ambientes escolares urbanos. Revista NBC. 2018 Jun;8(15):35-52.

6. Corassa JN et al. Biodiversidade da mirmecofauna em diferentes usos do solo no Norte MatoGrossense. Com Sci. 2015 Jun;6(2):154-163.

7. Silva TR, Fulco TO, Barbosa JV. Investigação de artrópodes em alimentos na transmissão de doenças. Episteme Transv. 2017;6(2):75-94.

8. Castro MM et al. The ant fauna of hospitals: advancements in public health and research priorities in Brazil. Rev Bras Entomol. 2015;59(1):77-83, doi:0.1016/j.rbe.2015.02.011

9. Menezes JS et al. Análise microbiológica de formigas capturadas em ambiente hospitalar da cidade de alfenas/MG. Rev Univ Vale Rio Verde. 2015;13(1):589-598.

10. Silva JAO, Ribeiro, ER. Controle de pragas e vetores de doenças em ambientes hospitalares. PUBVET. 2014 Ago;8(16):1940-2029.

11. Barreto RASS et al. Higienização das mãos: a adesão entre os profissionais de enfermagem da sala de recuperação pós-anestésica. Rev Eletr Enf. 2009;11(2):334-340.

12. Alves GG et al. Bactérias multidroga resistentes isoladas de formigas hospitalares. Investigação. 2011 Out;11(2):33-38.doi: 10.26843/investigacao.v11i2.503

13. Pereira RS, Ueno M. Formigas como veiculadoras de micro-organismos em ambiente hospitalar. Rev Soc Bras Med Trop. 2008;41(5): 492-495.

14. Vieira GD et al. Bactérias Gram positivas veiculadas por formigas em ambiente hospitalar de Porto Velho, Estado de Rondônia, Brasil. Rev Pan-Amaz Saude. 2013 Set;4(3): 33-36. doi:10.5123/S217662232013000300005

15. Martins MC, de Paula Júnior JD. Identification of Staphylococcus Aureus and Profile of Oxacillin Resistance in Hospital Environmental Ants. Int J An Sci Technol. 2018 Jan;1(1):15-18. doi: $10.11648 /$ j.jjast.20170101.13

16. Gonçalves MG et al. Associação entre formigas (Hymenoptera: Formicidae) e bactérias patogênicas em cinco hospitais do município de Pelotas, RS. Arq Inst Biol. 2011 Jun;78(2):287-295.

17. Silva GM et al. Formigas (Hymenoptera: Formicidae) como vetores de bactérias em ambiente hospitalar na cidade de São Luis-Maranhão. Rev Patol Trop. 2012 Ago;41(3):348-355, doi: 10.5216/rpt.v41i3.20750

18. Pereira RS, Ueno M. Presença de bactérias resistentes aos antibióticos em formigas coletadas em ambiente hospitalar. Rev Bioci. 2013;19(2):83-87.

19. Garcia TI et al. Perfil de resistência medicamentosa de bactérias isoladas de formigas de um hospital de Campo Mourão - PR. Rev Saúde Pesq. 2014 Ago;7(2):207-211.

20. Alves CMS et al. Mirmecofauna urbana hospital and its potential as agents of infectious vector. Vita et Sanitas. 2016 Dez;10(2):37-44.

21. Tanaka II, Viggiani AMFS, Person OC. Bactérias veiculadas por formigas em ambiente hospitalar. Arq Med ABC. 2007;32(2):60-63.

22. Silva EENF. Avaliação do potencial de formigas (Hymenoptera: formicidae) como vetores mecânicos de bactérias do gênero Staphylococcus no ambiente hospitalar. (Dissertação de mestrado). Natal: Universidade Federal do Rio Grande do Norte; 2009.

23. Jacobs C, Alves IA. Identificação de microrganismos veiculados por vetores mecânicos no ambiente hospitalar em uma cidade da região noroeste do estado Rio Grande do Sul. Rev Epidemiol Control Infect. 2014;4(4):238-242. doi:10.17058/reci.v4i4.4866

24. Bolton B. Synopsis and classification of Formicidae. Florida. Memoirs of the American Entomological Institute. 2003, $370 \mathrm{p}$.

25. Bolton B et al. Boltn's Catalogue of Ants of the World 1758-2005, 2007.

26. Conceição ES et al. Ant Community Evolution According to Aging in Brazilian Cocoa Tree Plantations. Sociobiol. 2019;66(1):33-43, doi:10.13102/sociobiology.v66i1.2705 
27. Schwingel I et al. Formigas (Hymenoptera: Formicidae) em centros de saúde da família de Chapecó, SC. Hygeia: Rev Bras Geogr Méd Saúde. 2016 Dez;12 (23):111-121.

28. Sá DMC. Diversidade de formicidae em ambiente hospitalar público do município de Macapá-Amapá. (Dissertação de mestrado). Macapá: Universidade Federal do Amapá, 2013.

29. Campos-Farinha AEC, Bueno OC. Formigas urbanas: comportamento e controle. Biológico, Palestra, 2004 Dez;66(1):47-48.

30. Pesquero MA et al. Formigas em ambiente hospitalar e seu potencial como transmissoras de bactérias. Neotrop Entomol. 2008 Ago;37(4):472-477.

31. Guerra SF, Conceição DM. Formigas carregadoras de bactérias no abrigo São Vicente de Paulo. Anuário da Prod Inic Cient 2010;10(11):45-51.

32. Carvalho APR, Silva CG, Fonseca AR. Diversidade de formigas em um hospital público no município de Chapadinha, Maranhão, Brasil. Rev Biol Ci Terra. 2011;11(2):67-73.

33. Santos A et al. Staphylococcus aureus: visitando uma cepa de importância hospitalar. J Bras Patol Med Lab. 2007 Dez;43(6):413-423.

34. Gaspar MDR, Busato CR, Severo E. Prevalência de infecções hospitalares em um hospital geral de alta complexidade no município de Ponta Grossa. Acta Scientiarum. Health Sci. 2012;34(1):23-29, doi: 10.4025/actascihealthsci.v34i1.8943.

35. Pfaller MR. Microbiologia médica. [Tradução Andreza Martins], 7. ed. Rio de Janeiro: Elsevier; 2014. 